This is a postprint version of the following published document:

Luzón, M., Corrales, T., Catalina, F., San Miguel, V., Ballesteros, C. \& Peinado, C. (2010): Hierarchically organized micellization of thermoresponsive rod-coil copolymers based on poly[oligo(ethylene glycol) methacrylate] and poly( $\varepsilon$-caprolactone). Journal of Polymer Science, Part A: Polymer Chemistry, 48 (22), pp. 4909-4921.

DOI: $\underline{10.1002 / \text { pola. } 24261}$

(C) 2010 Wiley Periodicals, Inc. 


\title{
Hierarchically Organized Micellization of Thermoresponsive Rod-Coil Copolymers Based on Poly[oligo(ethylene glycol) methacrylate] and Poly( $\varepsilon$-caprolactone)
}

\author{
MARIO LUZÓN,' TERESA CORRALES, ${ }^{1}$ FERNANDO CATALINA, ${ }^{1}$ VERÓNICA SAN MIGUEL, ${ }^{2}$ \\ CARMEN BALLESTEROS ${ }^{3}{ }^{\text {CARMEN PEINADO }}{ }^{1}$ \\ ${ }^{1}$ Instituto de Ciencia y Tecnología de Polímeros, C.S.I.C., C/Juan de la Cierva 3, ES28006 Madrid, Spain \\ ${ }^{2}$ Max Planck Institute for Polymer Research, Ackermannweg 10, DE55128 Mainz, Germany \\ ${ }^{3}$ Universidad Carlos III de Madrid, Avda. de la Universidad 30, ES28911 Leganés, Madrid \\ Correspondence to: C. Peinado (E-mail: cpeinado@ictp.csic.es) \\ Journal of Polymer Science: Part A: Polymer Chemistry, Vol. 48, 4909-4921 (2010) @ 2010 Wiley Periodicals, Inc.
}

\begin{abstract}
A series of amphiphilic triblock copolymers, poly [oligo(ethylene glycol) methacrylate] ${ }_{x}$-block-poly( $\varepsilon$-caprolactone)block-poly[oligo(ethylene glycol) methacrylate $]_{x}, \operatorname{POEGMA}_{\mathrm{Co}_{0}}(x)$, were synthesized. Formation of hydrophobic domains as cores of the micelles was studied by fluorescence spectroscopy. The critical micelle concentrations in aqueous solution were found to be in the range of circa $10^{-6} \mathrm{M}$. A novel methodology by modulated temperature differential scanning calorimetry was developed to determine critical micelle temperature. A significant concentration dependence of $\mathrm{cmt}$ was found. Dynamic light scattering measurements showed a bidispersed size distribution.
\end{abstract}

The micelles showed reversible dispersion/aggregation in response to temperature cycles with lower critical solution temperature between 75 and $85{ }^{\circ} \mathrm{C}$. The interplay of the two hydrophobic and one thermoresponsive macromolecular chains offers the chance to more complex morphologies. (c) 2010 Wiley Periodicals, Inc. J Polym Sci Part A: Polym Chem 48: 4909-4921, 2010

KEYWORDS: biodegradable; block copolymer; $\mathrm{cmc}$ and $\mathrm{cmt}$; comb-like polymer; grafting through; highly branched polymers; hierarchically self-assembly; micelles; thermoresponsive
INTRODUCTION Highly branched architectures are attracting a growing interest in the design of new polymers due to their behavior, structure and, specially, properties on various surfaces and interface in relationship to their structure. ${ }^{1}$ In particular, the control of the number of the branches allows fine-tuning physical properties and processing conditions. In addition to regular dendrimers, a wide variety of highly branched structures have been designed being one of the simplest graft polymers also called molecular brush or comb-like polymers. In contrast to typical graft copolymers, which are loosely grafted, the characteristic feature of brush molecules is high grafting density, currently one graft per backbone repeat unit. $^{2}$ The dense spacing of the side chains results in steric repulsion that induces an increase of the persistent length as well as the contour length of the polymer backbone.

The self assembly behavior of block copolymers is attracting considerable attention as a powerful strategy in the preparation of functional materials. Several authors have pointed out the importance of the architecture of copolymers in the self-organization behavior ${ }^{3-4}$ although the studies were restrained due to the lack of controlled synthetic routes for the preparation of well-defined block copolymers with low polydispersities. The development of new polymerization techniques, such as atom transfer radical polymerization (ATRP), reversible addition-fragmentation chain transfer (RAFT), and grafting-through, has allowed the synthesis of well-defined block copolymers with novel architectures giving rise to a growing number of papers devoted to their aggregation both in selective solvents and solid state. However, there is still a need to achieve more studies of self-assembly behavior of block copolymers with novel architectures to gain a deep knowledge of the relationship between the architecture of the copolymers and their self-assembly behavior. For instance, graft copolymers and rod-coil copolymers possess a complex structure giving rise to a complicated self-assembly behavior in solution and only, recently, the investigations are centered in these complex structures. ${ }^{5}$

ATRP is one of the most efficient methods to produce polymers with controlled molecular weight and polydispersity. ${ }^{6}$ The combination of this method with grafting approaches has been successfully used to prepare molecular brushes. ${ }^{7-9}$ In particular, macromonomer polymerization offers advantages on the control of both side chain polydispersity and 
grafting density over "grafting onto" and "grafting from" strategies. ${ }^{10-11}$ For instance, polymers of high branch density and uniform branch length can be obtained, which would not be easy to prepare by other synthetic approaches. Moreover, when macromonomer polymerization is carried out by ATRP the control of the reaction enables to obtain low main chain polydispersities.

Poly(ethylene glycol), PEG, is one of the most successful synthetic polymers in biotechnological and medical applications due to its biocompatibility and physiological solubility. The upcoming of oligo(ethylene oxide)-based macromonomers has allowed different macromolecular architectures that have been recognized as "smart" biorelevant materials. ${ }^{12-18}$ The polymerization of (meth)acrylates with PEG side chains has been carried out by ATRP under different conditions showing high polymerization rates in aqueous media. ${ }^{19}$ The limit of ATRP control has been explored through a detailed study of the solvent effects on ATRP of oligo(ethylene glycol) methacrylate. $^{20}$ In a new way of initiation process, ascorbic acid was used as a reducing agent of the $\mathrm{Cu}(\mathrm{II})$ complex resulting in generation of an active catalyst activator generated by electron transfer (AGET ATRP). ${ }^{21,22}$ Besides ATRP, other controlled radical polymerization (CRP) methods were used, such as reversible addition fragmentation transfer polymerization (RAFT) and nitroxide-mediated polymerization. ${ }^{23,24}$ Macromolecular engineering was performed by combination of PEG macromonomers polymerization with "click chemistry" ${ }^{25} \mathrm{~A}$ critical review of polymerization procedures of PEG-based macromonomers has been recently published by Neugebauer. ${ }^{26}$

In an attempt to obtain cylindrical brush-linear chain hybrid structures ATRP of a macromonomer, oligo(ethylene oxide) methacrylate $\left(M_{\mathrm{n}}=475 \mathrm{~g} / \mathrm{mol}\right)$ was carried out using a bifunctional macroinitiator based on low molecular weight $\left(M_{\mathrm{n}}=2000 \mathrm{~g} / \mathrm{mol}\right)$ poly( $\varepsilon$-caprolactone $)$, PCL. Following this procedure, we have prepared a new series of comb-like block copolymers. These macromolecules consist of a triblock polymeric backbone and oligo(ethylene oxide), oEO, grafted side chains (with identical chain length) in the endblocks. A central block of poly( $\varepsilon$-caprolactone) is connected to both terminal blocks which are poly[oligo(ethylene glycol) methacrylate]. In this series, the chain length of the central PCL block was maintained constant and varied that of the terminal fragments. Diblock and triblock copolymers containing poly[oligo(ethylene glycol methyl ether) methacrylate] blocks have been synthesized previously ${ }^{27,28}$ but not containing a central biodegradable block such as poly( $\varepsilon$-caprolactone). Lately, with an increase in environmental awareness, amphiphilic biodegradable copolymers offer interesting properties for biotechnological applications. ${ }^{29}$

These amphiphilic block copolymer brushes should exhibit interesting phase behavior. Thus, fluorescence spectroscopy, dynamic light scattering (DLS), TEM, and MTDSC studies were carried out to have a detailed knowledge of their selforganization behavior, including critical micelle concentration and temperature ( $\mathrm{cmc}$ and $\mathrm{cmt}$ ), micellar size, and aggregate morphology.

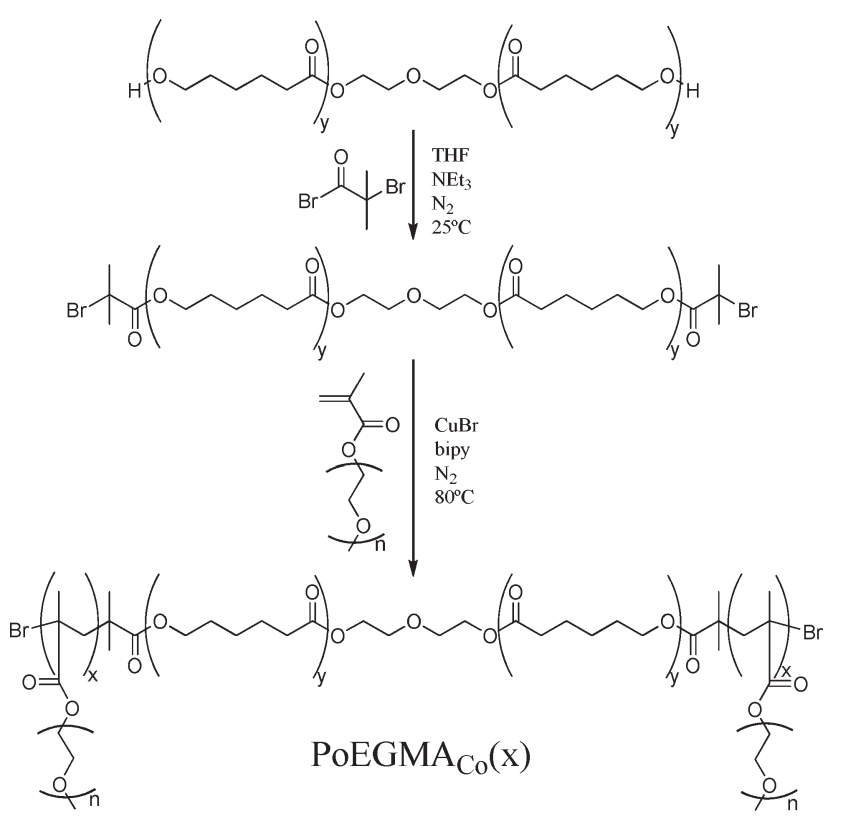

FIGURE 1 Scheme of synthesis of the triblock copolymers $\operatorname{POEGMA}_{\mathrm{Co}}(x)$.

These block copolymers are of interest both due to their practical applications, and from a fundamental perspective addressing hydrophobic-hydrophilic interactions, cloud points, gelation phenomena, and critical micelle concentrations. All the studies were carried out on the dilute region and thus, gelation process will be studied further.

\section{EXPERIMENTAL}

\section{Materials}

Poly(caprolactone) diol (Aldrich, $M_{\mathrm{n}} \sim 2000$ ), 2-bromo-2methylpropionyl bromide (Aldrich, 98\%), triethylamine (TEA, Fischer, 99\%, stored over potassium hydroxide pellets), 2,2'-bipyridine (Aldrich, $\geq 99 \%$ ). Monomethoxy-capped oligo (ethylene glycol) methacrylate (OEGMA; mean degree of polymerization is $8-9$, Aldrich). Copper bromide $(\mathrm{Cu}(\mathrm{I}) \mathrm{Br})$ (Aldrich, 99\%) was purified according to the method of Keller and Wycoff. $^{30}$ Toluene (Merck, $\geq 99.9 \%$ ) was degassed by bubbling with nitrogen for thirty minutes and water used in all experiments was MilliQ-grade. Acetonitrile (Panreac 99.7\%). Pyrene was recrystallized from ethanol.

\section{Synthesis of Amphiphilic Copolymers}

ABA triblock copolymers with different polymerization degrees of OEGMA were synthesized via a two-step reaction (Fig. 1). First, a dihydroxy-terminated poly( $\varepsilon$-caprolactone) was endfunctionalized using 2-bromoisobutyryl bromide. The resulting polymer was used as macroinitiator in the polymerization of OEGMA leading to triblock copolymers with a central core of PCL and POEGMA as terminal blocks of different lengths. A similar experimental procedure was recently reported. $^{31}$

\section{Synthesis of Macroinitiator}

2-Bromoisobutyryl bromide (9.3 $\mathrm{mL}, 75 \mathrm{mmol}$ ) and triethylamine (10.5 mL, $75 \mathrm{mmol}$ ) were added to an anhydrous THF 
solution (300 $\mathrm{mL}$ ) of $\alpha, \omega$-hydroxy terminated poly- $\varepsilon$-caprolactone $\left(M_{\mathrm{n}}=2000 \mathrm{~g} / \mathrm{mol}\right)$ under a nitrogen atmosphere. The reaction was carried out at ambient temperature overnight. The precipitated salts were removed via filtration and volatiles eliminated under reduced pressure. The obtained viscous oil product was dissolved in dichloromethane and washed with saturated $\mathrm{NaHCO}_{3}$ solution. The organic phase was dried over anhydrous magnesium sulphate and removed. The white solid product was eluted through a basic alumina column with dichloromethane (yield $=70 \%$ ).

${ }^{1} \mathbf{H}$ NMR $\left(\mathbf{C D C l}_{3}, 400 \mathbf{M H z}\right): \delta$ (ppm): $1.37\left[\mathrm{~m}, 17 \mathrm{OC}-\left(\mathrm{CH}_{2}\right)_{2}\right.$ $\left.-\mathrm{CH}_{2}-\left(\mathrm{CH}_{2}\right)_{2} \mathrm{O}_{\mathrm{PCL}}, 34 \mathrm{H}\right], 1.63\left[\mathrm{~m}, 17 \mathrm{OC}-\mathrm{CH}_{2}-\left(\mathrm{CH}_{2}\right)-\left(\mathrm{CH}_{2}\right)\right.$ $\left.-\left(\overline{\mathrm{CH}}_{2}\right)-\left(\mathrm{CH}_{2}\right)_{2}-\mathrm{O}_{\mathrm{PCL}}, 68 \mathrm{H}\right], 1.92\left(\mathrm{~s}, 1\left(\mathrm{CH}_{3}\right)_{2}-\mathrm{C}(\mathrm{Br})(\mathrm{CO}){ }_{\mathrm{PCL}}\right.$ $12 \mathrm{H}), 2.30\left[\mathrm{t}, 17 \mathrm{OC}-\mathrm{CH}_{2}-\left(\mathrm{CH}_{2}\right)_{4}-\mathrm{O}-{ }_{\mathrm{PCL}}, 34 \mathrm{H}\right], 4.05[\mathrm{t}, 27$ $\left.\mathrm{OC}-\left(\mathrm{CH}_{2}\right)_{4}-\mathrm{CH}_{2}-\mathrm{OCO}_{\mathrm{PCL}} 34 \mathrm{H}\right]$.

\section{Synthesis of Triblock Copolymers}

Four block copolymers were synthesized by changing the feed composition. The ratio between the concentrations of initiator, catalyst, and ligand were maintained constant in all the polymerizations $([\mathrm{I}]:[\mathrm{C}]:[\mathrm{L}]=1: 2: 4.2)$. The ratios of monomer concentration to initiator were 27:1 for POEG$\mathrm{MA}_{\mathrm{Co}}(13) ; 40: 1$ for POEGMA $\mathrm{Co}_{\mathrm{C}}(21) ; 70: 1$ for POEGMA $\mathrm{Co}_{\mathrm{O}}(29)$ and 75:1 for POEGMA Co $_{39}$ ).

A typical polymerization procedure is detailed below. PCL based macroinitiator (1 g, $0.45 \mathrm{mmol}$ ) was placed in a Schlenk tube and dissolved in deoxygenated toluene $(30 \mathrm{~mL})$. Oligo(ethylene glycol) methyl ether methacrylate (OEGMA; $9.9 \mathrm{~mL}, 22.5 \mathrm{mmol}$ ) was added to the solution. Then, the tube was sealed using a rubber septum and the mixture degassed via three freeze-pump-thaw cycles. $\mathrm{Cu}(\mathrm{I}) \mathrm{Br}(0.13 \mathrm{~g}$, $0.91 \mathrm{mmol}$ ) was added to the frozen mixture and it was deoxygenated by three vaccuum- $\mathrm{N}_{2}$ cycles. The reaction mixture, under nitrogen atmosphere, was heated at $80{ }^{\circ} \mathrm{C}$. When the temperature is reached, 2,2'-bipyridine $(0.30 \mathrm{~g}$, $1.91 \mathrm{mmol}$ ) ( $t=0$ ) was added. The reaction mixture immediately turned dark brown in color in addition of the ligand. Samples for analysis were taken periodically throughout the reaction to follow the polymerization by ${ }^{1} \mathrm{H}$ NMR in $\mathrm{CDCl}_{3}$ and GPC. Termination reaction occurred rapidly on exposure to air, as indicated by the color change from brown to green [oxidation of $\mathrm{Cu}$ (I) to $\mathrm{Cu}$ (II)]. Catalyst residues were eliminated by filtering through an activated basic alumina column. The volatiles were removed from the solution by rotary evaporation and under high vacuum at ambient temperature yielding a colorless polymer.

Bulk homopolymerization was carried out using essentially the same conditions as described above but using 2-bromoisobutyryl bromide as initiator instead of PCL-based macroinitiator.

${ }^{1} \mathbf{H}$ NMR ( $\left.\mathrm{CDCl}_{3}, 400 \mathrm{MHz}\right): \delta(\mathrm{ppm}): 0.84-1.05(\mathrm{~m}, 27$ $\left.\mathrm{CH}_{3}-\mathrm{C}_{\mathrm{OEGMA}}, 81 \mathrm{H}\right), 1.37\left[\mathrm{~m}, 17 \mathrm{OC}-\left(\mathrm{CH}_{2}\right)_{2}-\mathrm{CH}_{2}-\left(\mathrm{CH}_{2}\right)_{2} \mathrm{O}_{\mathrm{PCL}}\right.$

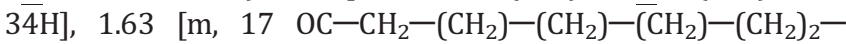
$\left.\mathrm{O}_{\mathrm{PCL}}, 68 \mathrm{H}\right], 1.92\left(\mathrm{~s}, 1\left(\mathrm{CH}_{3}\right)_{2}-\mathrm{C}(\mathrm{Br})(\mathrm{CO}){ }_{\mathrm{PCL}}, 12 \overline{\mathrm{H}}\right), 2.30[\mathrm{t}, 17$ $\left.\mathrm{OC}-\mathrm{CH}_{2}-\left(\mathrm{CH}_{2}\right)_{4}-\mathrm{O}-{ }_{\mathrm{PCL}}, 34 \mathrm{H}\right], 3.37$ [s, $27 \mathrm{CH}_{3}-\mathrm{O}-{ }_{\text {OEGMA, }}$ $81 \mathrm{H}], 3.64\left[\mathrm{~m}, 8 \times 27-\mathrm{O}-\left(\mathrm{CH}_{2}\right)-\mathrm{CH}_{2}-\mathrm{O}-{ }_{\text {OEGMA }}, 864 \mathrm{H}\right]$,
4.00-4.11 [m, $\left.27-\mathrm{OC}-\mathrm{O}-\left(\mathrm{CH}_{2}\right)-\mathrm{CH}_{2}-\mathrm{O}-{ }_{\text {OEGMA }}, 54 \mathrm{H}\right]+[\mathrm{t}$, $\left.17 \mathrm{OC}-\left(\mathrm{CH}_{2}\right)_{4}-\mathrm{CH}_{2}-\mathrm{OCO}_{\mathrm{PCL}} 3 \overline{4 \mathrm{H}}\right]$.

\section{Nuclear Magnetic Resonance}

${ }^{1} \mathrm{H}$ NMR and spectra were recorded in $\mathrm{CDCl}_{3}$ solution on a Varian INOVA-400 instrument operated at $400 \mathrm{MHz}$.

\section{Gel Permeation Chromatography}

Molecular weights and polydispersity measurements were carried out using a Waters 1515 Isocratic HPLC Pump system equipped with a Waters 2414 Refractive Index Detectors. Calibration was carried out using linear poly(ethylene oxide) standards (Polymer Standards Service Gmbh), ranging from $2.4 \times 10^{4}$ to $5.7 \times 10^{5} \mathrm{~g} \mathrm{~mol}^{-1}$. The mobile phase was ACN/Water $(15 \% \mathrm{v} / \mathrm{v})$ at a flow rate of $0.5 \mathrm{~mL} \mathrm{~min}^{-1}$. The system was equipped with a guard column Ultrahydrogel $6 \times 40 \mathrm{~mm}$ and two Ultrahydrogel $7.8 \times 300 \mathrm{~mm}$ mixed columns in series, thermostated at $25{ }^{\circ} \mathrm{C}$.

\section{Optical Transmittance Measurements}

Optical transmittance of block copolymer was measured at $550 \mathrm{~nm}$ with a Lambda $35 \mathrm{UV}-\mathrm{Vis}$ spectrometer (PerkinElmer). The sample cell was thermostated in a refrigerated circulator bath Thermomix 1441 (B.BRAUN) at different temperatures from 10 to $90{ }^{\circ} \mathrm{C}$ before measurements. The lower critical solution temperature (LCST) of the polymer solution was defined as the temperature at the onset of the decrease in optical transmittance. This method seems to be accurately utilized only when two prerequisites are satisfied. The first prerequisite is that all the initial transmittance values of the curves are the same. The second is that the phase-transition ranges of all the curves are similar. ${ }^{32}$

\section{Fluorescence Spectroscopy Measurements}

The cmc's were determined by a fluorescence probe technique using pyrene as a fluorescent probe. Pyrene stock solutions were prepared in acetonitrile. Fluorescence emission spectra were recorded on a Perkin-Elmer LS-55 spectrofluorimeter. Sample solutions were prepared by dissolving a known amount of polymer in water. The effective concentration of probe was maintained at $10^{-6} \mathrm{M}$ in all the aqueous solutions. Fluorescence emission spectra of the probe were recorded in the range 350-700 $\mathrm{nm}$ using a fixed excitation wavelength of $337 \mathrm{~nm}$. All the spectra were corrected using the response curve of the photomultiplier. The temperature was controlled with a thermostate Thermomix 1441 (B.BRAUN).

The cmc was determined from the plot of the $I_{1} / I_{3}$ versus copolymer concentration following the sigmoidal Boltzman fitting procedure used by Leiva and col. $^{33}$

The partition coefficient of pyrene in copolymer solutions were determined by the method described by Kabanov and col. $^{34,35}$ The fraction of hydrophobic pyrene that was incorporated in the micelles $(\alpha)$ was determined from fluorescence intensity at $392 \mathrm{~nm}$, as a function of copolymer concentration, according to the eq 1 :

$$
\alpha=\frac{I-I_{\min }}{I_{\max }-I_{\min }}
$$


where $I$ is the fluorescence intensity at $392 \mathrm{~nm}, I_{\min }$ is the intensity in water, and $I_{\max }$ is the maximum intensity.

The partition coefficient, $P$, and the volume fraction of the micellar phase, $\theta$, for a specific copolymer concentration is given by eq 2 :

$$
\alpha=\frac{P \theta}{P \theta+1-\theta}
$$

where $P=C_{m} / C_{w}$ and $C_{m}$ and $C_{w}$ are the pyrene concentration in the micellar microphase and in the water phase, respectively. The volume fraction of micellar phase is given by eq 3 :

$$
\theta=0.01(C-\mathrm{cmc}) v
$$

where $C$ is the total concentration of copolymer, $v$ is the partial volume fraction of copolymer, and $\mathrm{cmc}$ is critical micellar concentration ( $\mathrm{cmc}$ ). By combining the eqs 2 and 3, eq 4 is obtained:

$$
\frac{1}{\alpha}=\frac{1}{0.01 P v(C-\mathrm{cmc})}+1-\frac{1}{P}
$$

In accord with eq 4 , plots of $1 / \alpha$ versus $1 /(C-$ cac $)$ yield straight lines with slopes equal to $1 /(0.01 \mathrm{P} v)$, from which the partitioning coefficient can be determined. In their determination of the partitioning coefficient of benzo[a]pyrene into poly(caprolactone)-block-poly(ethylene oxide) micelles, Lim Soo and co-workers ${ }^{36}$ used a value of $1.0 \mathrm{~cm}^{3} / \mathrm{g}$ for $v$.

\section{Calorimetry Measurements}

Differential scanning calorimetry (DSC) measurements were performed by using a DSC $823^{\mathrm{e}}$-Mettler Toledo equipped with sample robot and cooled by Julabo FT400 intracooler and controlled with a STARe software 9.10 version. Aluminium standard crucibles with $20 \mu \mathrm{L}$ of sample were used for analyses that were carried out under a nitrogen atmosphere. Indium and water were used for temperature and enthalpy calibration.

TOPEM mode was chosen as temperature modulated DSC method. Instead of being based upon a periodic modulation of the heating rate, as is the situation with temperature modulated DSC (MTDSC) techniques, TOPEM uses a stochastic modulation of the heating or cooling rate by means of random pulses of temperature. This feature has the advantage that a set of experiments require only scan of the samples but not for the blank as in other MTDSC techniques. ${ }^{37}$ The parameters selected were: temperature range for the scan was from 10 to $50{ }^{\circ} \mathrm{C}$ to cover the cmt; the underlying heating rate was $0.1 \mathrm{~K} \mathrm{~min}^{-1}$; the amplitude of the temperature pulse took values of $0.05 \mathrm{~K}$; and the switching time range, which limits the duration of the pulses, had a minimum of $30 \mathrm{~s}$ and a maximum of $60 \mathrm{~s}$.

Data analysis was carried out using TOPEM software. To calculate the response function for the system, the evaluation window was selected covering a region of the data in which there is no transition. The TOPEM evaluation yields the curve of $c \mathrm{p} 0$, the "quasi-static" specific heat capacity and the separation of correlated and noncorrelated components of the heat flow with respect to the heating rate, which are related to the reversing and nonreversing heat flows in the usual MTDSC terminology.

\section{Dynamic Light Scattering}

Solutions for light scattering measurements were prepared by dissolving the tribock copolymer in double filtered Millipore water and filtered again after solution preparation with PTFE filters (pore diameter $0.45 \mu \mathrm{m}$ ). DLS measurements were performed using a Malvern Zetasizer Nano spectrometer equipped with a $4 \mathrm{~mW}$ helium neon laser operating at $633 \mathrm{~nm}$. All measurements were carried out with $1 \mathrm{~g} / \mathrm{L}$ copolymer solution at a scattering angle of $173^{\circ}$. Temperature in the cells was kept constant to $18^{\circ} \mathrm{C}$ for the determination of micelle sizes. Also temperature was varied between $10-50{ }^{\circ} \mathrm{C}$ allowing equilibration for at least $30 \mathrm{~min}$ at each temperature prior to measurement using $0.01 \mathrm{~g} / \mathrm{L}$ copolymer solution. For each of these conditions a minimum of three measurements was made. The correlation function from DLS was analyzed by the CONTIN algorithm to obtain distributions of decay rate. ${ }^{38}$ The decay rate distributions provided distributions of apparent diffusion coefficient,

$$
D=\Gamma / q^{2}
$$

where $q=(4 \pi n / \lambda) \sin (\theta / 2) ; n$ is the refractive index and $\theta$ is the angle of measurement.

The apparent hydrodynamic diameter was obtained through the Stokes-Einstein eq 6:

$$
D_{h}=\frac{k T}{3 \pi n D}
$$

\section{Transmission Electron Microscopy Measurements}

Transmission electron microscopy (TEM) with high resolution (HRTEM) was carried out in a Philips Tecnai 20F FEG microscope operating at $200 \mathrm{kV}$, equipped with a scanning transmission electron microscopy (STEM) module, with a dark field high angle annular detector for Z-contrast imaging. Aggregation studies were carried out by electron diffraction pattern simulation, using fast Fourier transform (FFT) of the HRTEM images. To prepare the TEM samples, $5 \mu \mathrm{L}$ of an aqueous solution $(0.1 \mathrm{~g} / \mathrm{L})$ of block copolymer micelles was dropped onto a carbon-coated copper grid and the water droplet was allowed to evaporate slowly in air.

\section{RESULTS}

The "grafting through" approach, combined with ATRP, was successfully used for the synthesis of a new series of comblike triblock copolymers. The synthetic route exploited a preformed, terminally functionalized polymer chain that formed the core of the macromolecules, reacting with a methacrylic monomer bearing oligomeric side chains based on poly(ethylene glycol). These macromolecules consist of a triblock ABA polymeric backbone and poly(ethylene glycol) 
TABLE 1 Feed Composition in the ATRP and Composition of Copolymers and Homopolymer, Together with $M_{\mathrm{n}}$ Determined by NMR and GPC

\begin{tabular}{|c|c|c|c|c|c|c|c|}
\hline Sample & $f_{\mathrm{PoEGMA}}{ }^{\mathrm{a}}$ & $F_{\mathrm{PoEGMA}}{ }^{\mathrm{b}}$ & $\begin{array}{l}M_{\mathrm{n}, \mathrm{NMR}}{ }^{\mathrm{c}} \\
(\mathrm{g} / \mathrm{mol})\end{array}$ & $\begin{array}{l}M_{\mathrm{n}, \mathrm{GPC}}{ }^{\mathrm{d}} \\
(\mathrm{g} / \mathrm{mol})\end{array}$ & $\begin{array}{l}M_{\mathrm{n}, \mathrm{th}}^{\mathrm{e}} \\
(\mathrm{g} / \mathrm{mol})\end{array}$ & PD & $M_{\mathrm{w}} / M_{\mathrm{n}}^{\mathrm{f}}$ \\
\hline PoEGMA $_{\mathrm{co}}(13)$ & 0.85 & 0.86 & 14,350 & 5,910 & 13,910 & 13 & 1.64 \\
\hline PoEGMA $_{\text {co }}(21)$ & 0.91 & 0.91 & 21,560 & 9,280 & 21,770 & 21 & 1.47 \\
\hline PoEGMA $_{\mathrm{co}}(29)$ & 0.93 & 0.93 & 29,070 & 11,270 & 24,900 & 29 & 1.40 \\
\hline PoEGMA $_{\mathrm{co}}(39)$ & 0.94 & 0.94 & 39,050 & 17,770 & 36,110 & 39 & 1.49 \\
\hline PoEGMA & 1.00 & 1.00 & 18,700 & 19,970 & 20,000 & 41 & 1.51 \\
\hline $\begin{array}{l}\text { a Molar fraction o } \\
\text { b Molar fraction o } \\
{ }^{c} \text { Determined by } \\
{ }^{\mathrm{d}} \text { Determined by } \\
\text { e } \bar{M}_{\mathrm{n}, \mathrm{th}}=(([\text { Monor } \\
{ }^{\mathrm{f}} \text { Polydispersity in }\end{array}$ & $\begin{array}{l}\text { oEGMA in } t \\
\text { oEGMA in } t \\
\text { R. } \\
\text { C, standards } \\
r]_{0} \times M_{w, \text { mon }} \\
x \text { determine }\end{array}$ & $\begin{array}{l}\text { feed. } \\
\text { copolymer. } \\
\text { f poly(ethyle } \\
\times \text { Conversi } \\
\text { y GPC. }\end{array}$ & $\begin{array}{l}\text { oxide)s. } \\
\text { )/[Macroini }\end{array}$ & tor $\left.]_{0}\right)+\bar{M}_{\mathrm{n}}$ & roinitiator & & \\
\hline \multicolumn{8}{|c|}{$\begin{array}{l}\text { The copolymers were named as } \operatorname{PoEGMA}(x) \text {, where } x \text { denoted the polymerization degree (PD) of each } \\
\text { PoEGMA block. }\end{array}$} \\
\hline
\end{tabular}

grafted side chains (with identical chain length) in the endblocks. A central block of poly(e-caprolactone) was connected to both terminal blocks. In this series, the chain length of the central block was maintained constant and varied that of terminal fragments. As the degree of polymerization of the poly[oligo(ethylene glycol) methacrylate] segment increased the main chain became longer than the side chain and the terminal blocks exhibited a cylindrical brush structure.

ABA block copolymers were synthesized from difunctional macroinitiator PCL using copper-mediated CRP as shown in Figure 1. The ATRP macroinitiator was prepared by coupling the hydroxyl functionalities of a commercial $\alpha, \omega$-dihydroxy terminal polycaprolactone with 2-bromo-2-methylpropionyl bromide. Polymerization of OEGMA was carried out at $80{ }^{\circ} \mathrm{C}$ in toluene using bipyridine, bipy, as a ligand and $\mathrm{Cu}(\mathrm{I}) \mathrm{Br}$ as a catalyst. Although OEGMA (8-9 repeat units) is a watersoluble monomer, the polymerization reaction was carried out in toluene because of the hydrophobic character of the PCL macroinitiator. There are several examples of successful polymerization of water-soluble monomers but in nonaqueous media. ${ }^{39,40}$

Table 1 summarizes feed and copolymers composition, together with $M_{\mathrm{n}}$ determined by ${ }^{1} \mathrm{H}$ NMR, GPC, and by elemental analysis. The copolymers were named as $\operatorname{POEGMA}_{\mathrm{Co}}(x)$, where $x$ denoted the polymerization degree of each POEGMA block. In other words, $x$ denote the number of poly(ethylene glycol) side chains in each of the end-blocks. The above procedure was followed for the polymerization of OEGMA $\left(M_{\mathrm{n}}=475\right.$ and DP $\left.=8-9\right)$ giving rise to water soluble copolymers at room temperature.

Number average molecular weights, $M_{\mathrm{n}}$, were determined from ${ }^{1} \mathrm{H}$ NMR spectra on the basis of the intensity ratio of signals at $4.1 \mathrm{ppm}$ assigned to the methylene bond of the methacrylic group and that at 1.63 ppm for two methylenes of PCL. As the signal at $4.1 \mathrm{ppm}$ was also present at the beginning of the reaction the intensity at $1.63 \mathrm{ppm}$ was used as internal reference. These values were fairly close to those theoretically calculated on the basis of the $[M]_{0} /[]_{0}$ and macromonomer conversion. Slight differences increases as degree of polymerization and may be attributed to the polydispersity of the macromonomer. The commercial macromonomer OEGMA is a mixture of oligomers having a $M_{\mathrm{n}}$ of $475 \mathrm{~g} / \mathrm{mol}$. A large discrepancy was observed between GPC and NMR results (Table 1) and several reasons may account for these differences. It should be expected large differences between the relationship hydrodynamic volume-molecular weight for these comb-like copolymers compared with that for poly(ethylene oxide) samples used as standards in GPC calibration. $^{41}$ Moreover, anomalous elution behavior has been demonstrated for other cylindrical brushes. ${ }^{42}$ All the polymers showed monomodal distributions and a relatively narrow molecular weight distribution by GPC.

Kinetics analysis was performed by sampling the reactions at regular time intervals and monitoring monomer conversion by ${ }^{1} \mathrm{H}$ NMR. The signals of the double bond protons (5.6 and $6.1 \mathrm{ppm}$ ) disappeared, the peak of the polymethacrylate backbone appeared at $4.1 \mathrm{ppm}$ and the signal at $4.3 \mathrm{ppm}$ (assigned to methylene attached to the ester carbonyl group of the macromonomer) was used as a reference. The comparison of monomer and polymer signals allowed the monomer conversion to be determined with good reliability. A semilogarithmic plot of monomer conversion versus reaction time resulted linear up to high conversions using different composition feeds (Fig. 2). This indicates that the polymerization was first order with respect to monomer and the concentration of growing radicals was constant during the reaction. Kinetic studies showed that polymerization occurred after an induction time but a conversion of nearly $90 \%$ was typically achieved within $120 \mathrm{~min}$, and the polymerization was found to be first order even up to very high conversions. Figure 2(b) also shows that the plot of $M_{\mathrm{n}}$ versus conversion is linear with molar mass determined from NMR. All these results suggest a controlled radical mechanism under these conditions. 

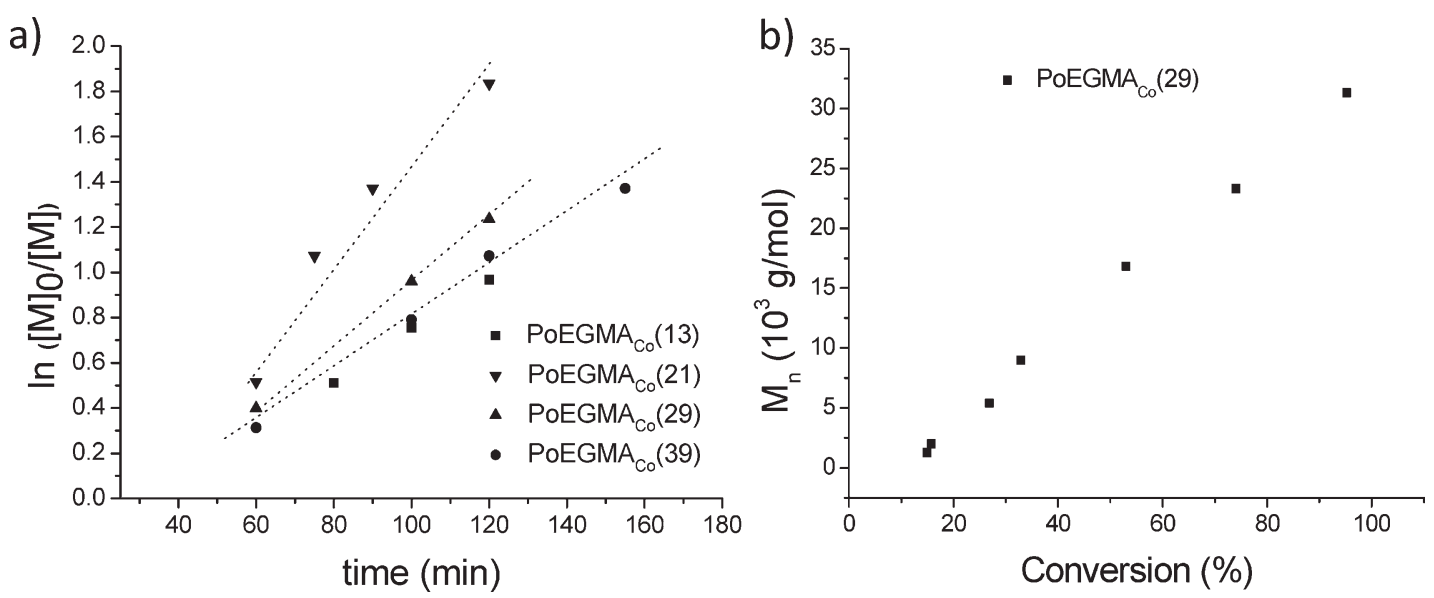

FIGURE 2 Kinetics of polymerization of OEGMA using a bifunctional macroinitiator based in poly $(\varepsilon$-caprolactone) in toluene media at $80{ }^{\circ} \mathrm{C}$. The relative molar ratios of OEGMA:initiator were 27:1 for POEGMA $\mathrm{Co}_{\mathrm{O}}(13), 40: 1$ for POEGMA $\mathrm{A}_{\mathrm{Co}}(21)$, 70:1 for POEGMA Co $(29)$, and 75:1 for POEGMA Co $(39)$.

The fluorescence emission spectra of pyrene in aqueous solutions of copolymers POEGMA $\mathrm{Co}_{(x)}$ were measured at different concentrations. Fluorescence intensity increases as copolymer concentration. The ratio between the intensities at two wavelengths, $\lambda_{1}=372 \mathrm{~nm}$ and $\lambda_{2}=382 \mathrm{~nm}$, was used to determine $\mathrm{cmc}$ at a fixed temperature of $21{ }^{\circ} \mathrm{C}$ as far as it senses the micropolarity changes because of the aggregates formation. The ratio of $I_{1} / I_{3}$ versus copolymer concentration is plotted in Figure 3. The fluorescence intensity ratio decreases as copolymer concentration increases indicating the solubilization of pyrene in a more hydrophobic environment. Two important features should be pointed out. A drastic change of intensity ratio was observed and it occurred in a wide range of concentration.

The cmc and partition coefficients values were determined by fluorescence spectroscopy and are compiled in Table 2 . As micelles were not formed abruptly, but rather over a concentration range, an onset of micelle formation was determined using a mathematical calculation. When the second derivative of $I_{1} / I_{3}$ to copolymer concentration is calculated, the $\mathrm{cmc}$ onset value is obtained from its minimum. All the copolymers displayed very low $\mathrm{cmc}$ values with the values in the range circa $10^{-6} \mathrm{M}$. The $\mathrm{cmc}$ values decreased by increasing the degree of polymerization of POEGMA blocks from 13 to 39, which was also accompanied by a decrease of the partition coefficient. This decrease indicates that hydrophobic interactions become stronger as the POEGMA chain length decreases.

The ratio $I_{1} / I_{3}$ verified the apolar nature of the micelle core. Partitioning coefficient also decreased as molecular weight increased indicating that micelle interior become more hydrophilic as a result of the inclusion of some EO units.

The analysis of excimer and monomer emission from pyrene (at 482 and $392 \mathrm{~nm}$, respectively) allowed distinguishing between static and dynamic mechanism of micelles formation. Figure 4 shows the plot of $I_{\mathrm{E}} / I_{\mathrm{M}}$ as a function of the concentration of POEGMA $\mathrm{Co}_{\mathrm{C}}(39)$. A maximum value of $I_{\mathrm{E}} / I_{\mathrm{M}}$ was observed at $10^{-2} \mathrm{~g} / \mathrm{L}$ corresponding to the concentration of copolymer at which the number of aggregates increases and gives rise to partitioning of pyrene between different micelles, diminishes the pyrene concentration per micelle and thus, excimer concentration. A dynamic behavior in micelle formation was confirmed by the overlapping of the excitation spectrum of the monomer with the excitation spectrum of the excimer. ${ }^{43}$

One of the characteristics features of OEGMA based polymers is that their micellization behavior is strongly temperature dependent in aqueous media. The thermal induced self-orga-

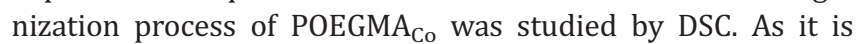
well-known, ${ }^{44,45}$ water of solvation may adopt an ice-like structure around the PEO hydrophilic blocks, which disappears as temperature increases. On the other hand, Karlström ${ }^{46}$ suggested that the increasing hydrophobicity of PEO blocks was due to a conformational change from polar to

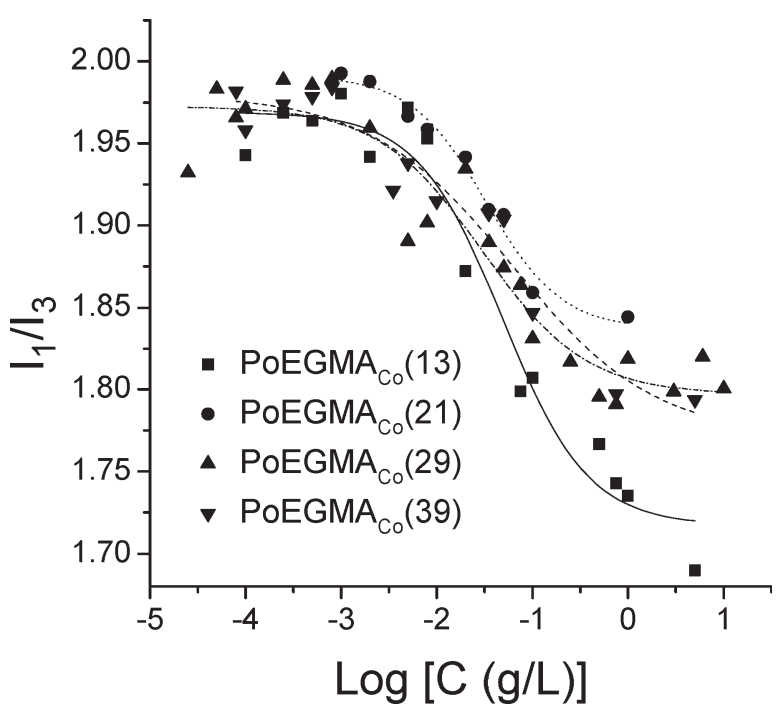

FIGURE 3 Plot of the $l_{1} / l_{3}$ ratio versus copolymer concentration. 
TABLE 2 Critical Micellar Concentration, Partition Coefficient of Pyrene between Micelles and Water and Hydrodynamic Diameter of Micelles for the PoEGMA Triblock Copolymers

$\begin{array}{llllllr}\text { Sample } & \begin{array}{l}M_{\mathrm{n}, \mathrm{NMR}} \\ (\mathrm{g} / \mathrm{mol})\end{array} & \begin{array}{l}\mathrm{cmc}_{\mathrm{onset}} \\ (\mathrm{mg} / \mathrm{L})\end{array} & \begin{array}{l}\mathrm{cmc} \\ (\mathrm{mg} / \mathrm{L})\end{array} & \begin{array}{l}\mathrm{cmc} \\ \left(10^{-6} \mathrm{M}\right)\end{array} & \begin{array}{l}\text { Partition } \\ \text { coef. }\end{array} & \begin{array}{r}D_{\mathrm{h}} \\ (\mathrm{nm})^{\mathrm{a}}\end{array} \\ \text { PoEGMA }_{\mathrm{Co}}(13) & 14350 & 12.5 & 37.2 & 2.6 & 3,075 & 5.5 \\ \text { PoEGMA }_{\mathrm{Co}_{0}}(21) & 21560 & 8.9 & 32.0 & 1.6 & 1,546 & 10.5 \\ \text { PoEGMA }_{\mathrm{Co}_{0}}(29) & 29070 & 7.2 & 29.7 & 1.0 & 567 & 16.4 \\ \text { PoEGMA }_{\text {Co }}(39) & 39050 & 3.9 & 25.4 & 0.6 & 178 & 23.4\end{array}$

${ }^{\text {a }} D_{\mathrm{h}}$ was determined for copolymer solutions of $1 \mathrm{~g} / \mathrm{L}$.

nonpolar configuration of PEO block that results in reduction in polymer water interaction and the subsequent aggregation. The temperature at which micellization occurs is called critical micellization temperature, $\mathrm{cmt}$, and the surfactant concentration at this temperature is the cmc. The thermally induced association process allows preparing micelles by dissolving the water soluble copolymers precluding the use of more complex methods that involve cosolvents and subsequent dialysis.

The cmt values were determined by temperature modulated DSC using TOPEM technique, in which stochastic temperature modulations are superimposed on the underlying rate of a conventional DSC scan. These modulations consist of temperature pulses, of fixed magnitude and alternating sign, with random durations within limits specified in the experimental conditions, whereas periodic modulation of the heating rate is used in other modulated DSC techniques. The modulation creates high instantaneous heating rates which increases sensitivity. The low underlying constant heating rate is used to get better resolution. Similar experiments using conventional DSC were unsuccessful to determine cmt.

Figure 5 shows the heat flow variations of the nonreversing curve with temperature for a series of POEGMA $\mathrm{Co}_{2}(29)$ solutions. A sharp increase was observed at different temperatures, depending on copolymer concentration. After the rapid

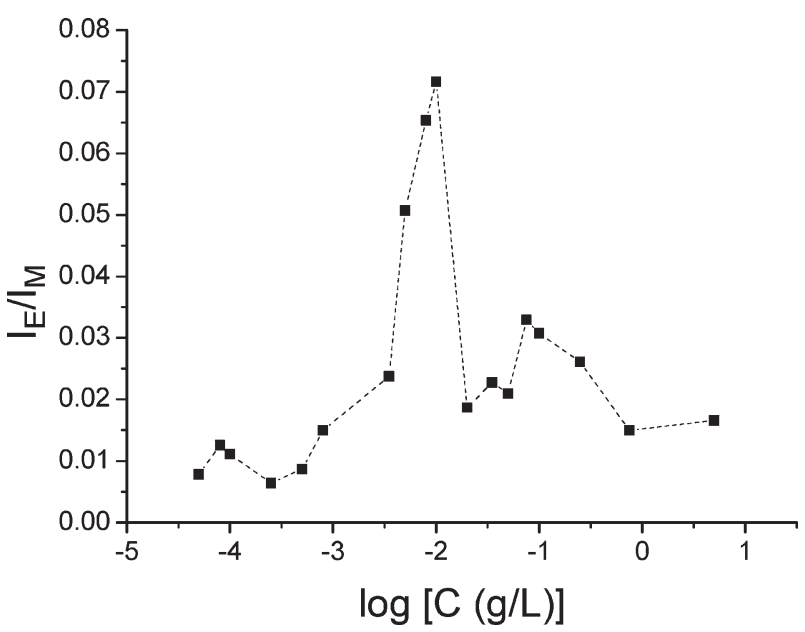

FIGURE 4 Plot of $I_{E} / I_{M}$ as a function of the concentration of $\operatorname{POEGMA}_{\mathrm{Co}_{0}}(39)$. increase, heat flow value becomes zero at a certain temperature, which was ascribed to the cmt (Table 3).

For sake of comparison, we measured fluorescence intensity ratio of pyrene as a function of temperature. The $I_{1} / I_{3}$ plots versus temperature did not permit an accurate determination of cmt and this may be related with the partitioning of the pyrene between the two microphases.

The cmt values determined by DSC were compared with those obtained measuring fluorescence intensity of Nile Red as a function of temperature for POEGMA $\mathrm{Po}_{\text {o }}$ solutions of increasing concentration. A sharp increase of fluorescence intensity with temperature occurred over a narrow range of temperature and the cmt was identified as the point at which a tangent drawn to the ascending linear portion of the curve intersects the extrapolated fluorescence intensity in the absence of aggregation. The data are collected in Table 3 together with the MTDSC data. These $\mathrm{cmt}$ values calculated from fluorescence spectroscopy are shown to be in good agreement with those calculated from modulated temperature DSC. The small differences reflect the differences in the sensitivity of the methods. The fact that both techniques provides comparable estimates for $\mathrm{cmt}$ points out that the process under investigation by MTDSC is the micellization

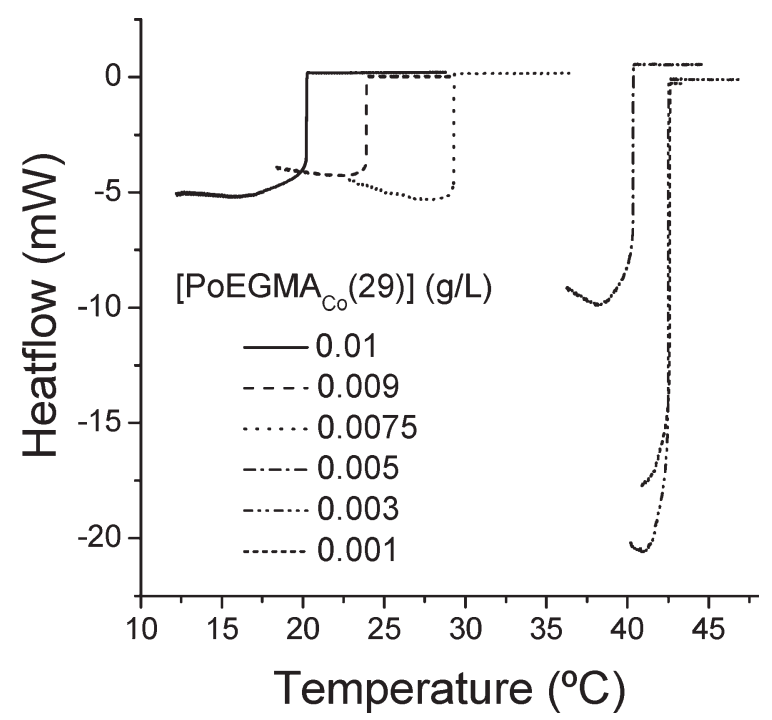

FIGURE 5 Heat flow variations of the nonreversing curve with temperature for a series of POEGMA ${ }_{C_{0}}(29)$ solutions. 
TABLE 3 The cmt Values Determined by MTDSC for Copolymer PoEGMA Co $(29)$ at Different Concentrations Compared with Those Determined by Fluorescence Method

$\begin{array}{llc}{[\text { PoEGMA] (g/L) }} & \text { cmt (MTDSC) }\left({ }^{\circ} \mathrm{C}\right) & \mathrm{cmt}(\text { Nile Red })\left({ }^{\circ} \mathrm{C}\right) \\ 0.0100 & 19.7 \pm 0.5 & 21.3 \pm 1.0 \\ 0.0090 & 23.4 \pm 0.5 & 25.5 \pm 1.0 \\ 0.0075 & 28.6 \pm 0.5 & 26.4 \pm 1.0 \\ 0.0050 & 39.5 \pm 0.5 & 36.2 \pm 1.0 \\ 0.0030 & 41.0 \pm 0.5 & - \\ 0.001 & 40.9 \pm 0.5 & -\end{array}$

process and shows the self-consistency of the new modulated temperature DSC method supporting its reliability.

Figure 6 shows the semilogarithmic plot of $\mathrm{cmt}$, determined by MTDSC, as a function of copolymer concentration. It is observed that increasing copolymer concentration reduces the cmt, whereas the cmt value for the homopolymer poly (oligoethylene glycol methacrylate) changes slightly over a wide range of concentration. Another striking feature is that the concentration dependence of $\mathrm{cmt}$ becomes more pronounced at higher concentrations.

For further evidence that the POEGMA copolymers did selfaggregate above $\mathrm{cmc}$ and $\mathrm{cmt}$, micellar aggregates were studied by DLS to measure their hydrodynamic diameter and their population distribution in terms of size. The relaxation time distributions obtained by the inverse Laplace transformation of the correlation functions from four different copolymers showed two populations. Additionally, the kurtosis of the distributions were rather broad (polydispersity index $>0.2$ ), which should be ascribed to the polymer polydispersity and/or the presence of micellar clusters. The apparent hydrodynamic diameter of micelles, $D_{\mathrm{h}}$, determined through the Stokes-Einstein formula, are compiled in Table 2

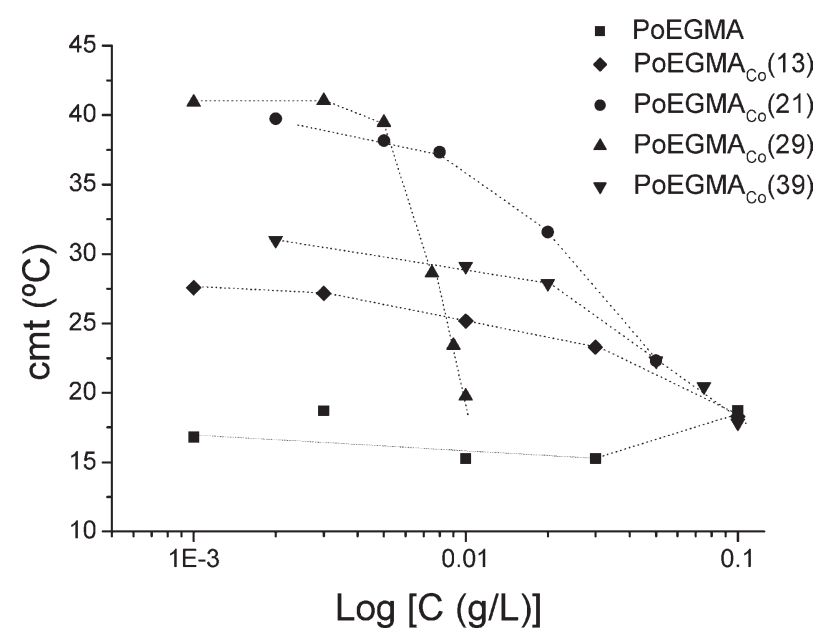

FIGURE 6 Semilogarithmic plot of $\mathrm{cmt}$, determined by TMDSC, against copolymer concentration. Homopolymer POEGMA is included for comparison. Dotted lines are provided to guide the reader. together with molecular mass. As the chain length of the terminal blocks increases dimensions of micelles grow following an almost linear trend.

To address about the state of aggregation of these polymers hydrodynamic diameters as a function of the temperature were determined (Fig. 7). The aim was to decide whether this association leads to well-defined assemblies, which remains constant over a wide range of concentration/temperature or to aggregates, which vary constantly with conditions changes. The occurrence of two scattering populations of particles was also found. Besides micelles which have a $D_{\mathrm{h}}=25$ to $45 \mathrm{~nm}$ depending on copolymer composition, one additional population with $D_{\mathrm{h}} \sim 150-250 \mathrm{~nm}$, which is attributed to the aggregates.

The morphology of the aggregates was examined by TEM and individual micelles can be distinguished particularly well on the micrograph of POEGMA $\mathrm{Co}_{\mathrm{C}}(21)$ in Figure 8. The sizes determined from TEM images, circa $34 \mathrm{~nm}$, were in good agreement with those obtained from DLS measurements. This micrograph only just allows the row of micelles to be discerned as circular dark dots, suggesting a spherical shape. Although these results reveal the basic structural elements of micellar arrangement, the imaging and resolution allows a poor characterization of individual micellar size and shape. It has to be pointed out that the morphology of the aggregates depends on copolymer concentration and can be controlled by temperature. Therefore, high-resolution transmission electron microscopy (HR-TEM) and electron-diffraction pattern simulation by FFT was used to analyze the selfassembly structures. Herein, we report the formation of cubic aggregates from the block copolymer POEGMA $\mathrm{Co}_{\mathrm{C}}(21)$ as concentration increases [Fig. 8(b)]. Micrographs showed dispersed cubic phases in the aqueous systems of the block copolymers.

Figure 9 shows HRTEM image, the image is characterized by two arrays of perpendicular image fringes. From FFTs of Figure 9 simulated diffraction peaks were observed at ratios of $1: \sqrt{ } 2$; and angles of $90^{\circ}$, which can be related with a

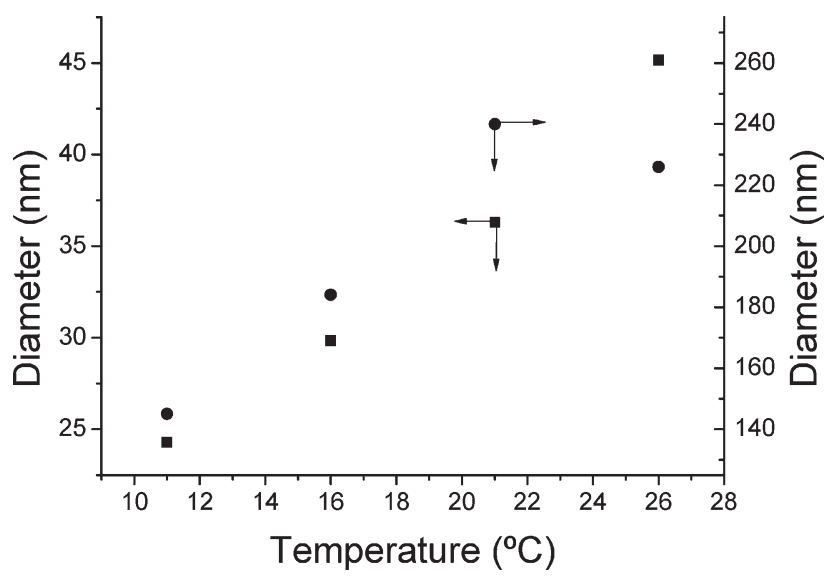

FIGURE 7 Apparent hydrodynamic diameter as a function of temperature for the copolymer POEGMA $\mathrm{Co}(29)$ at $0.009 \mathrm{~g} / \mathrm{L}$. 

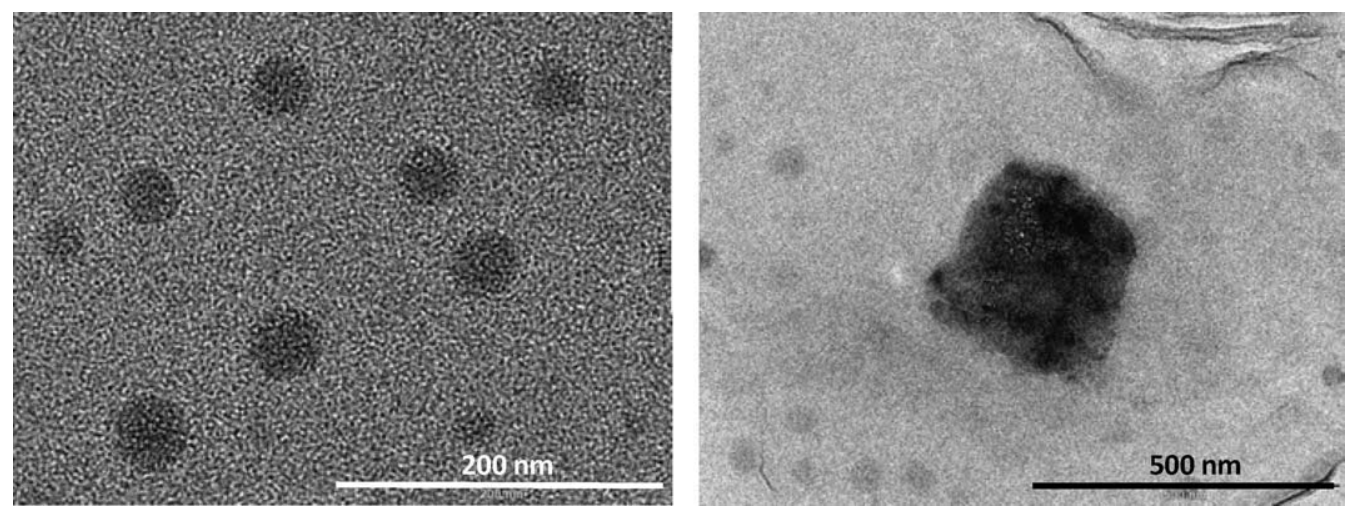

FIGURE 8 (a) TEM micropictures of POEGMA Co (29) micelles and (b) Bright Field TEM of POEGMA Co (21). Scale bar: (a) 200 nm and (b) $500 \mathrm{~nm}$.

primitive cubic structure. FFT analysis yielded a mean cubic edge of $4.5 \AA$.

In Figure 10, the STEM micrographs allowed to visualize cubic structures and raspberry-like multicomponent micelles/ nanosponges, which are formed by the interaction of micelles. STEM-HAAD Z-contrast image of a nanosponge is shown in Figure 10(b).

The transmittance of aqueous polymer solutions was monitored at $550 \mathrm{~nm}$ at a heating rate of $1{ }^{\circ} \mathrm{C} / \mathrm{min}$ for samples POEGMA $_{\mathrm{Co}}(29)$ and POEGMA $\mathrm{Co}_{2}(21)$ in presence and absence of $\mathrm{NaCl}$. These copolymers showed a LCST and their aqueous solutions started to become cloudy around $91{ }^{\circ} \mathrm{C}$ for POEGMA $_{\mathrm{Co}}(21)$, thus, the transmittance rapidly dropped to $0 \%$. In the other hand, the LCST decreased with increasing molecular weight of the copolymer and thus, the LCST value for POEGMA Co $_{2}(29)$ was $80^{\circ} \mathrm{C}$. The LCST was concentration dependent and its value for POEGMA ${ }_{\text {Co }}(29)$ decreased from 89 to $80{ }^{\circ} \mathrm{C}$ as the concentration increases from 0.5 to $1 \mathrm{~g} / \mathrm{L}$.
These results are consistent with previous reports for welldefined poly(oligo(ethylene oxide) methacrylates) homopolymers. ${ }^{47}$ The addition of sodium chloride to POEGMA $\mathrm{Co}(29)$ aqueous solution led to a decrease of the LCST from $80{ }^{\circ} \mathrm{C}$ (in its absence) to $76{ }^{\circ} \mathrm{C}$ for $1 \mathrm{M} \mathrm{NaCl}$.

\section{DISCUSSION}

It is noteworthy that the ATRP reaction of the methacrylic monomer of oligoethylene glycol proceeds to high conversion degree in spite of the osmotic repulsion that should be experienced by a macromonomer diffusing toward the highly crowded growing chain ends in dilute solution. In the other hand, as OEGMA is a sterically congested monomer, its termination rate constant is several orders of magnitude lower than that of conventional methacrylates, which is expected to lead to improved living character. Therefore, using a bifunctional macroinitiator, we open a chemical pathway to obtain a significantly larger main chain than side chain
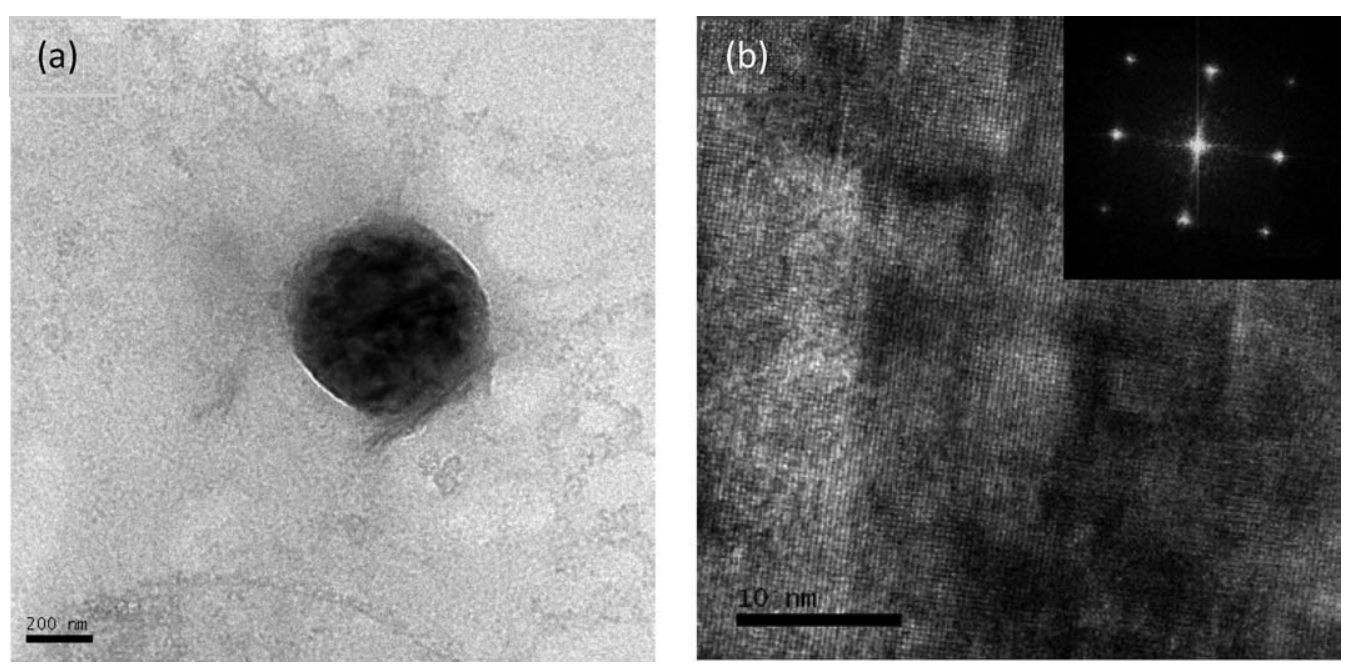

FIGURE 9 HRTEM image of POEGMA Co (21). Inset shows electron diffraction pattern simulation by Fast Fourier Transform of the HRTEM image. FTP pattern can be identified as a cubic plane the distances in the real space are indicated at the spots. Scale bar: (a) $200 \mathrm{~nm}$ and (b) $10 \mathrm{~nm}$. 

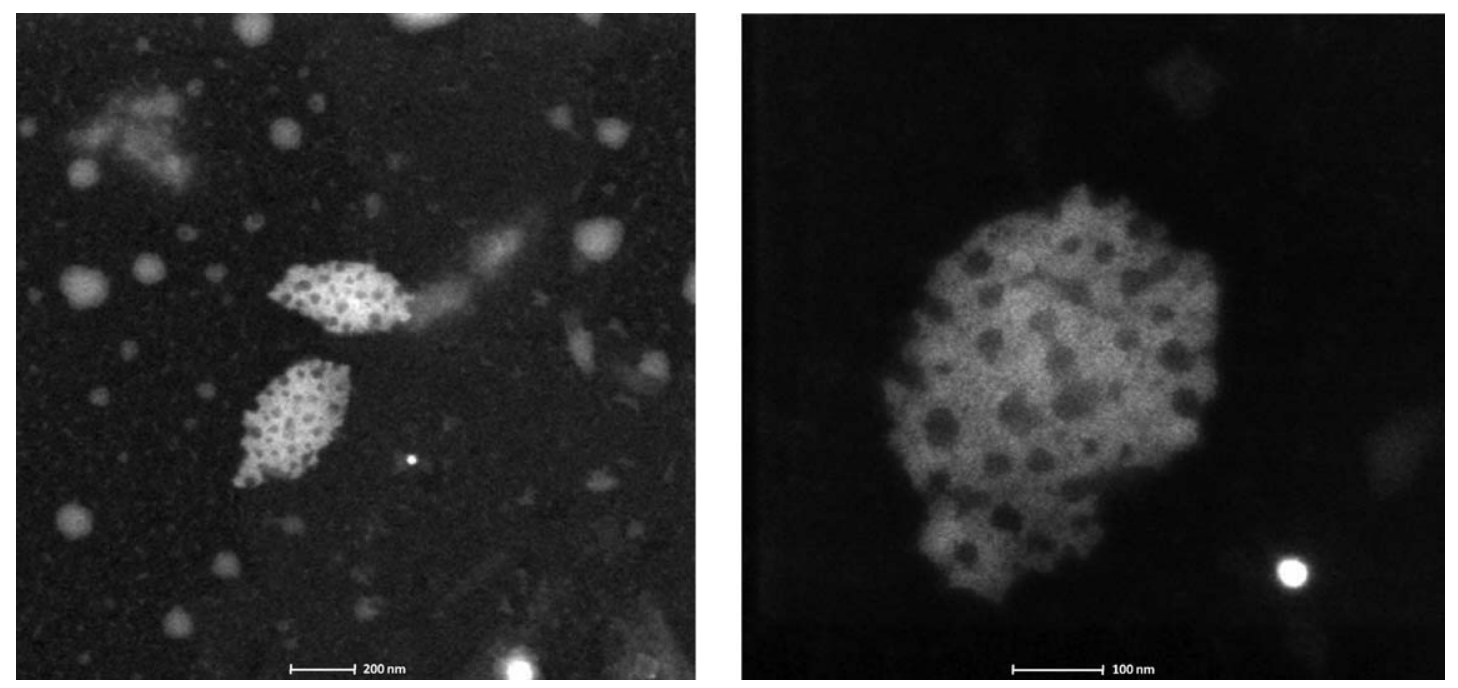

FIGURE 10 (a) STEM-HAAD low resolution Z-contrast image of POEGMA $\mathrm{Co}_{\mathrm{o}}(21)$. Cubic structures and nanosponges are visible. The elements with higher atomic number, or higher density, appear brighter. (b) STEM-HAAD Z-contrast image of a nanosponge. Scale bar: (a) $200 \mathrm{~nm}$ and (b) $100 \mathrm{~nm}$.

degree of polymerization, which has been difficult to reach by living anionic or cationic polymerization. ${ }^{48}$

In this series of copolymers, the water solubility diminishes due to the fact that the increase of the ethylene oxide, EO, hydrophilic moieties seems to be counterbalanced by the entropy penalty associated with the increased number of monomer units. Thus, the $\mathrm{cmc}$ values diminished as degree

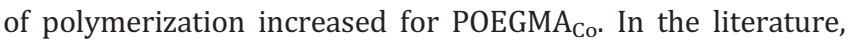
contradictory behaviors have been observed for micelle formation from copolymers containing poly(ethylene oxide) blocks. Some nonionic surfactants exhibited an increase of the $\mathrm{cmc}$ with the size of EO chain. ${ }^{49}$ However, Alexandris et al. $^{50,51}$ found the opposite behavior for a wide series of block copolymers based on ethylene oxide and propylene oxide (Pluronics or Poloxamers). Independently of the number of EO or PO, larger polymers associated at lower concentrations, even if the increase of size was due to EO units. Also, an increase in the length of the hydrophilic block resulted in a decrease in the $\mathrm{cmc}$ when the length of the hydrophobic block was held constant for diblock copolymers, PEG- $b$-PCL. ${ }^{52}$

It is not only the hydrophilic-lipophilic balance the factor that governs the association of these copolymers into diverse nanostructured particles; rather, it is also that the specific topology of the different blocks significantly influences the micellar morphology. The self assembly behavior of these rod-coil copolymers was governed by the effect of chain topology on conformational entropy, which restricted their ability to stretch, to accommodate packing within selfassembled structures and their ability to gain conformational entropy when dissolved in solution. Therefore, the broad concentration range of the micellization process suggests a large deviation from the phase separation model and low cooperativity of the micellization process.
In a polymeric solution, there is a competition between enthalpic interaction and entropic effect, which determine the aggregation behavior of the copolymers. ${ }^{53}$ Under the $\mathrm{cmt}$, the entropic effects play a key role, whereas the enthalpic contribution dominates over entropic effects by increasing temperature, which results in the aggregation of copolymers and microphase separation. A new MTDSC based method has been presented here to provide estimates of $\mathrm{cmt}$. This approach exploits the fact that the chemical potential of the only component (water) in the gaseous phase has to be equal to that of the same component in the more complex phase because the formations of the microphase-separated block copolymer/water. In this way, and because of the entropy of the block copolymer before and after the phase segregation is comparable, ${ }^{54}$ the only factor to be considered in this analysis should be the chemical potential, going from a mixture of components where water is interacting with the block copolymer to another where it is not. Thus, the heat transfer, as detected by DSC, after phase transition at temperatures higher than $\mathrm{cmt}$ is near zero. The proposed approach is perfectly general and can be applied to any volatile component (e.g., organic solvents and water) in contact with a block copolymer. Here, it has to be pointed out that the success in these measurements was to use nonhermetically sealed aluminum pans allowing water evaporation, and thus working at atmospheric pressure (constant pressure) at cmt. These values were in good agreement with those obtained by fluorescence spectroscopy.

The concentration dependence of temperature at which micellization occurs is readily explained in thermodynamics terms. It is expected that any increase in the amphiphilic copolymer concentration may give rise to a growth of micelle concentration in agreement with the mass action description of the aggregation process. Moreover, the temperature of aggregation should be reduced by increasing copolymer 
concentration as a consequence of the endothermic nature of the micelle formation. It is therefore observed that increasing copolymer concentration reduces the $\mathrm{cmt}$, whereas the $\mathrm{cmt}$ value for the homopolymer poly(oligoethylene glycol methacrylate) changes slightly over a wide range of concentration. Another striking feature is that the concentration dependence of cmt becomes more pronounced at higher concentrations for the copolymers. This behavior reveals a hierarchically-organized self-assembly where thermally induced premicellization preludes the micellization of these triblock copolymers.

DLS studies indicated that the copolymers form large and loose micellar aggregates due to a low micellar packaging efficiency induced by corona branching. It is expected that a high degree of hydration because of hydrogen bond formation with the ether oxygen contribute to bigger aggregates. Additionally, as the corona of polymeric micelles consists of densely packed chains, entropic repulsion would disfavor any fusion between micelles giving rise to bicontinuous structures. TEM provided evidence of this kind of structures and nanosponges were observed.

The short PCL chain length as long as with T-responsiveness of the densely branched of poly(OEGMA) are responsible of hierarchically self-assembly. The autoassociation model proposed here is based on a premicellization of poly(OEGMA) induced by temperature increase follow up by aggregates formation with concentration increase. Premicelles consisted of the lowest size aggregates where PCL chain was incorporated to the core, polymethacrylate formed the shell and poly (oligoethylene glycol) chains were the corona. It has to be pointed out that even though the polymethacrylate block is not water soluble, it has surface active groups (e.g., ester groups) thereby possessing a relatively strong affinity on the water or, at least highest than that of PCL. As copolymer concentration was increased bigger and looser aggregates were formed, which were interpreted as soft matter dispersions with ordered inner structure stabilized by poly(oligoethylene glycol)methacrylate chains. The latest feature is explained by the large cross-sectional area of cylindrical shape of poly (OEGMA) result in little entanglement between the chains. It is assumed that these triblock copolymers provides steric stabilization by having its poly( $\varepsilon$-caprolactone) chains adsorbed on the surface of the stabilized particle, whereas its more hydrophilic oligo(ethylene glycol) ends extend into the external continuous phase.

In the other hand, sizes increased with temperature indicating the occurrence of aggregates, which tend to associate at higher temperature to form more organized structures with a large increase in the micelle aggregation number. This temperature-dependent assembly is attributed to the increasing insolubility of POEGMA side chains with increasing temperatures that favors self-association by enhanced hydrophobic association. Hydration-dehydration processes are responsible for modification in chain packing and modulate supramolecular association modes. For these copolymers, the semibranched topology of the POEGMA segments played a key role in the micellization behavior enabling a magnification of the size due to an increase of aggregation number as the desolvation of poly(oxyethylene) chains proceeds.

Finally, a hierarchically-organized self-assembly where thermally induced premicellization preludes the aggregation of the triblock copolymers was identified. In these rod-coil copolymers, the thermoresponsive rod chains provide a unique self-organization mechanism that yields morphologies which are truly nanostructured materials, with structure on the molecular, internal mesophase, and nanoparticle length scales. Also, the formation of compartmentalized micelles can be understood by the interplay of several factors and, thus, are the result of equilibrating the different interactions between the three chemically different blocks (two hydrophobic and one thermoresponsive) and the solvent, which competes with the efficiency of rod packing under the geometric constraint of micellar objects. Multiblock copolymers have an extra level of control, introduced by the supra interaction between blocks, which give rise to more complex morphologies. ${ }^{55}$ We have observed that spherical micelles pack to primitive cubic phases, as the concentration increased, leading to a decrease of the local curvature.

\section{CONCLUSIONS}

The ATRP polymerization of the macromonomer OEGMA (89 repeat units) using a bifunctional PCL macroinitiator has led to a series of rod-coil-rod block copolymers where the rods were formed by densely branched fragments. As the PCL block length was fixed the hydrophilic-hydrophobic balance of the block copolymers was adjusted by varying the degree of polymerization of POEGMA block; this was achieved by changing the monomer-to-macroinitiator ratio from 27:1 to $75: 1$.

The self-assembly behavior is governed by hydrophilic-lipophilic balance as well as topological effects. Thus, the cmc values were low enough as corresponding to amphiphilic block copolymers and both $\mathrm{cmc}$ and partitioning coefficient decreased as the degree of polymerization increased. The latest feature is explained by the inclusion of oligoethylene glycol chains in the interior of the micelle because of the steric repulsion induced by densely branched fragments.

The thermoresponsiveness of these copolymers was studied by MTDSC and turbidimetry. Self-assembly was temperature and concentration dependent for the copolymers POEGMA $_{\mathrm{Co}}$, containing a central PCL block, in contrast with the POEGMA homopolymer. As concentration increases the cmt diminished for the copolymers and remained constant for the homopolymer.

Because of the specific architecture (topology, relative block lengths) and the nature of the blocks of the macromolecule, an unprecedented structural diversity and multifunctionality was observed. This has allowed us to identify a range of two-dimensional ordered particles, which may be tuned by changing both the temperature and the concentration of 
polymer solutions. The interplay of the two hydrophobic chains and one thermoresponsive macromolecular chain offers the chance to more complex morphologies with potential applications for lipid-like drug delivery systems.

The authors are indebted to Francesç Catala, from MettlerToledo, for valuable discussions. The authors are grateful to LABMET, TEM Laboratory associated to the Comunidad Autónoma de Madrid network and Mr. J. González-Casablanca for his cooperation with the TEM images. The authors would like to thank the Plan Nacional I+D+I (Ministerio de Ciencia e Innovación) for financial support (MAT2009-09671) as well as the Comunidad Autónoma de Madrid for the funding through I+D Program (S0505/MAT-0227).

\section{REFERENCES}

1 Peleshanko, S.; Tsukruk, V. V. Prog Polym Sci 2008, 33, 523-580.

2 Tsukahara, Y.; Tsutsumi, K.; Yamashita, Y.; Shimada, S. Macromolecules 1990, 23, 5201-5208.

3 Hadjiantoniou, N. A.; Triftaridou, A. I.; Kafouris, D.; Gradzielski, M.; Patrickios, C. S. Macromolecules 2009, 42, 5492-5498.

4 Riess, G. Prog Polym Sci 2003, 28, 1107-1170.

5 Cheng, L.; Cao, D. Langmuir 2009, 25, 2749-2756.

6 Durmaz, Y. Y.; Kumbaraci, V.; Demirel, A. L.; Talinli, N.; Yagci, Y. Macromolecules 2009, 42, 3743-3749.

7 Borner, H. G.; Duran, D.; Matyjaszewski, K.; da Silva, M.; Sheiko, S. S. Macromolecules 2002, 35, 3387-3394.

8 McCullough, L. A.; Dufour, B.; Matyjaszewski, K. J Polym Sci Part A: Polym Chem 2009, 47, 5386-5396.

9 Yin, J.; Ge, Z.; Liu, H.; Liu, S. Journal of Polymer Science: Part A: Polymer Chemistry 2009, 47, 2608-2619.

10 Börner, H. G.; Beers, K. L.; Matyjaszewski, K.; Sheiko, S. S.; Möller, M. Macromolecules 2001, 34, 4375-4383.

11 Defleux, A.; Schappacher, M. Macromolecules 2000, 33, 7371-7377.

12 Edwards, E. W.; Chanana, M.; Wang, D.; Mohwald, H. Angew Chem Int Ed 2008, 47, 320-323.

13 Chanana, M.; Jahn, S.; Georgieva, R.; Lutz, J.-F.; Bäumler, H.; Wang, D. Chem Mater 2009, 21 1906-1914.

14 Boyer, C.; Whittaker, M. R.; Luzón, M.; Davis, T. Macromolecules 2009, 42, 6917-6926.

15 Lutz, J. F. J Polym Sci Part A: Polym Chem 2008, 46, 3459-3470.

16 Oyane, A.; Ishizone, T.; Uchida, M.; Furukawa, K.; Ushida, T. Adv Mater 2005, 17, 2329-2332.

17 Wischerhoff, E.; Uhlig, K.; Lankenau, A.; Borner, H. G.; Laschewsky, A.; Duschl, C.; Lutz, J. F. Angew Chem Int Ed 2008, 47, 5666-5668.

18 Tan, I.; Zarafshani, Z.; Lutz, J. F.; Titirici, M. M. ACS Appl Mater Interf 2009, 1, 1869-1872.
19 Wang, X.-S.; Armes, S. P. Macromolecules 2000, 33, 6640-6647.

20 Bergenudd, H.; Coullerez, G.; Jonsson, M.; Malmström, E. Macromolecules 2009, 42, 3302-3308.

21 Oh, J. K.; Min, K.; Matyjaszewski, K. Macromolecules 2006, 39 3161-3167.

22 Oh, J. K.; Perineau, F.; Charleux, B.; Matyjaszewski, K. J Polym Sci Part A: Polym Chem 2009, 47, 1771-1781.

23 Lessard, B.; Marić, M. Macromolecules 2008, 41, 78707880.

24 Li, Z.; Zhang, K.; Ma, J.; Cheng, C.; Wooley, K. L. J Polym Sci Part A: Polym Chem 2009, 47, 5557-5563.

25 Lutz, J.-F.; Börner, H. G.; Weichenhan, K. Macromolecules 2006, 39, 6376-6383.

26 Neugebauer, D. Polym Int 2007, 56, 1469-1498.

27 Holder, S. J.; Durand, G. G.; Yeoh, C.-T.; Illi, E.; Hardy, N. J.; Richardson, T. H. J Polym Sci Part A: Polym Chem 2008, 46, 7739-7756.

28 Mertoglu, M.; Garnier, S.; Laschewsky, A.; Skrabania, K.; Storsberg, J. Polymer 2005, 46, 7726-7740.

29 San Miguel, V.; Peinado, C.; Catalina, F.; Abrusci, C. Internat Biodet Biodeg 2009, 63, 217-223.

30 Keller, R. N.; Wycoff, H. D. Inorg Synth 1947, 2, 1-4.

31 San Miguel, V.; Limer, A. J.; Haddleton, D. M.; Catalina, F.; Peinado, C. Eur Polym J 2008, 44, 3853-3863.

32 Liu, X.; Cheng, F.; Liu, H.; Chen, Y. Soft Matter 2008, 4, 1991-1994.

33 Leiva, A.; Quina, F. H.; Araneda, E.; Gargallo, L.; Radic, D. J Colloid Interf Sci 2007, 310, 136-143.

34 Kabanov, A.; Nazarova, I.; Astafieva, I.; Batrakova, E. V.; Alakhov, V.; Yaroslavov, A.; Kabanov, V. Macromolecules 1995, 28, 2303-2314.

35 Kozlov, M. Y.; Melik-Nubarov, N. S.; Batrakova, E. V.; Kabanov, A. V. Macromolecules 2000, 33, 3305-3313.

36 Lim Soo, P.; Luo, L.; Maysinger, D.; Eisenberg, A. Langmuir 2002, 18, 9996-10004.

37 Fraga, I.; Montserrat, S.; Hutchinson, J. M. J Thermal Anal Calorim 2007, 87, 119-124.

38 Wyn, B. Light Scattering: Principle and Development; Clarendon Press: Oxford, 1996.

39 Neugebauer, D. Z. Y.; Pakula, Y. T.; Sheiko, S. S.; Matyjaszewski, K. Macromolecules 2003, 36, 6746-6755.

40 Yamamoto, S. I.; Pietrasik, J.; Matyjaszewski, K. J Polym Sci Part A: Polym Chem 2008, 46, 194-202.

$41 \mathrm{Gu}$, L.; Shen, Z.; Lu, G.; Zhang, X.; Huang, X. Macromolecules $2007,40,4486-4493$.

42 Gerle, M.; Fischer, K.; Roos, S.; Müller, A. H. E.; Schmidt, M. Macromolecules 1999, 32, 2629-2637.

43 Nakashima, Y. L. a. K. Langmuir 2003, 19, 548-553.

44 Kjellander, R.; Florin, E. J. J Chem Soc Faraday Trans 1981, 77, 2053-2077. 
45 Linse, P. Macromolecules 1993, 26, 4437-4449.

46 Karlström, G. J Phys Chem 1985, 89, 4962-4964.

47 Lutz, J. F.; Akdemir, O.; Hoth, A. J Am Chem Soc 2006, 128, 13046-13047.

48 Neiser, M. W.; Okuda, J.; Schmidt, M. Macromolecules 2003, 36, 5437-5439.

49 Atwood, D.; Forence, A. T. Surfactants Systems their Chemistry, Pharmacy and Biology; Chapman and Hall: London, 1983.

50 Alexandris, P.; Holzwarth, J. F.; Hatton, T. A. J Am Oil Chem Soc 1995, 72, 823-826.

51 Alexandris, P.; Holzwarth, J. F.; Hatton, T. A. Macromolecules 1994, 27, 2414-2425.

52 Allen, C.; Maysinger, D.; Eisenberg, A. Colloids Surf B 1999, 16, 3-27.

53 Suek, N. W.; Lamm, M. H. Langmuir 2008, 24, 30303036.

54 Park, M. J.; Balsara, N. P.; Jackson, A. Macromolecules 2009, 42, 6808-6815.

55 Berlepsch, H.; Böttcher, C.; Skrabania, K.; Laschewsky, A. Chem Commun 2009, 17, 2290-2292. 